\title{
Conceptual Metaphors in Theory and Practice
}

\author{
Narine Aghajanyan \\ Kh. Abovyan Armenian State Pedagogical University
}

\begin{abstract}
Languages can be viewed as metaphorical due to their linguistic and cultural background. The connection between the image and abstract meaning can be understood in cognitive terms using a particular concept of metaphor. The notion "metaphor" can be applied to any linguistic unit used in an indirect sense. In contrast to previous theories of metaphor, conceptual metaphor theory proposes that metaphor is not just a language unit but a fundamental part of human thought. The aim of this paper is to bring forward different aspects of theoretical studies on this important issue and show how new realities in politics automatically cause metaphorization of language.
\end{abstract}

Key words: metaphor, conceptual metaphor, mapping, two-dimensional perception, political discourse, concept.

\section{Introduction}

Metaphor is not only an element of language, but also one of the ways of organizing thought. Our usual conceptual system within the framework of which we both think and act is fundamentally metaphorical in nature. Metaphor generates new concepts in the field of thinking that reflect the newly acquired experience and knowledge, a new and different vision of it. The conceptual metaphor, transferring conceptual structures from certain fragments of reality to other, provides conceptualization and representation of these fragments by analogy with the already established system of concepts. Conceptual metaphor is more often used to describe those fragments of reality, the knowledge of which is negligible for humans. Such metaphors are designed to broaden the boundaries of a particular area and often act as figurative models. 


\section{Theoretical Framework of Conceptual Metaphors}

Conceptual metaphors play an important role in shaping language identity. Thanks to the theory of J. Lakoff, M. Johnson, and M. Turner, - metaphor is considered primarily as a cognitive phenomenon, as a way of thinking, as a mechanism constantly present in our consciousness J. Lakoff proved that the figurative vision of reality is expressed in the language of metaphoric conceptual systems, through which we are able to represent an indefinite abstract concept or phenomenon through an understandable, concrete image (Lakoff, Johnson 2003). Metaphorical conceptual systems are observed in the language of poetry (Lakoff, Turner 1989), science (Gusev 1984, 1988), literary novels (Chafe 1967), and also in the language of politics and newspapers (Lakoff, Johnson 2003). With the introduction of a new, cognitive paradigm, the metaphor was viewed as the result of a cognitive process, "when thoughts interact within a single word or expression and create meaning that is precisely the result of this interaction (A. Richards)" (Antropova 1996:12). If we try to define a newspaper article metaphorically, we may conclude that it is an entity authored by a journalist. It is based on a certain person's ideas about the world, the problems that exist in it, the possibilities for solving them, and the role of the personality in solving these problems, offering either their own model of the world or acting in accordance with a certain pragmatic task.

Metaphorization differs from the phenomenon of the "normal" literal language in a number of ways. This problem was investigated by many linguists. Some authors represent the process of metaphorization as a mechanism, a two-dimensional perception of literal and transferable meanings that is manifested in a figurative metaphor as if it is a simultaneous vision of two pictures (Arutyunova 1990). Other researchers interpret the functioning of the metaphor as the work of a filter that flashes information corresponding to the schema and obscures information that does not correspond to it (Reddy 1980). Despite the fact that some researchers continue to argue that the term "metaphor" can only be applied to the language system (Jackendoff, Aoron 1991), most researchers focus on its cognitive, conceptual aspect. This idea was most clearly expressed by J. Lakoff and M. Johnson. According to their 
approach conceptual metaphors are the result of a mapping, conceptual mapping of knowledge from one conceptual domain into another. D. Allbritton (1994) attributes the metaphor to cognitive rather than purely linguistic phenomena. J. Lakoff and M. Johnson consider the essence of the metaphor in the understanding and perception of one phenomenon in terms of the other. In this case, the phenomenon could not be taken in isolation, as in the cases of the traditional approach to metaphor. It should be viewed as an integral picture of the visible real world, which is used to represent and comprehend a voluminous and multidimensional abstract phenomenon. So, for example, the movement of capital in the financial sphere can be estimated in terms of fluid flow inflow/outflow of capital, financial injections. G. Lakoff and M. Johnson claim that all metaphors are structural as they map structures to structures, and ontological as they create target domain entities, and at the same time many of them are orientational. Ontological metaphors are present in events, actions, emotions, ideas, etc. as an existing being or substance. Orientational metaphors have a spatial orientation. According to J. Lakoff and M. Turner, the smallest groups of conceptual metaphors are figurative metaphors, formed by means of pattern matching, and not by transferring meaning from one area to another (Lakoff, Turner 1989).

In modern studies, there are also three other types of metaphors: nominative, figurative and cognitive (Arutyunova 1990). The cognitive approach to the creation of metaphors is described as a three dimensional complicated process consisting of a superficial language as well as semantic and cognitive processes. Taken separately, these processes do not provide a full explanation of the mechanism for creating the image, whereas applied sequentially, they are able to present it as a more complex phenomenon of language and as a component of human cognition.

Exploring the role of the conceptual metaphor in language and cognitive processes, D. Allbritton argues that conceptual metaphors form special information structures that accumulate information and determine its representation in memory (Allbritton 1994). He calls these structures metaphor based schemas. For example, the conceptual metaphor "Crime is a Disease" does 
not exist in complete isolation, but generates a series of information blocks that form a whole meaningful chain. Additional information is generated in our mind about a certain phenomenon without direct appeal to it or its careful study. For example, metaphorically, the source of the concept of crime can be predictable, crime can be eradicated, etc. Metaphorical schemes perform the function of systematizing an information request. For example, M. Black found that the script "visiting a restaurant" could determine the order of requesting information from the text (Black 1962). S. Glucksberg, B. Keysar, M. McGlone have a somewhat different view on conceptual metaphors. They claim that conceptual metaphors might not reflect the existing intersections between parts in our brain represented in long-term memory. On the contrary, they suggest that such intersections can only be created in the process of metaphorical perception. To perceive it our mind creates categories to which the metaphoric theme can be attached. From this point of view, the metaphors "Crime is a Disease", "Love is a Long Journey" do not present specially organized knowledge, but rather a way of understanding the concepts of "crime" and "love" that can arise in the reader when reading the text and using these metaphors.

Metaphorization is one of the most significant ways of influencing the audience. The use of a conceptual metaphor in a political text is not only a powerful mechanism that penetrates into the consciousness. It also enables to reconstruct a person's consciousness and change it. It is traditionally believed that the use of a conceptual metaphor is the most beneficial and effective way for creating an image, since these phenomena do not have any corresponding special linguistic modes of expression. In this case, the metaphor becomes a description of one area of activity by means of language tools from another area. Researchers often compare the effectiveness of the metaphorical way of communication in mass media with the effectiveness of the psychotherapeutic session. In the opinion of D. Gordon, both in the case of communication in the field of mass media and in a psychotherapeutic session the main goal is to provide a pragmatic impact, each metaphorical element of information presented is understood and interpreted in application to the author's own 
model of the world. If in the case of a psychotherapeutic session the therapist occasionally compares his interpretation of the client's problem with the interpretation of the client himself, in the case of media impact, it is a comparison of the metaphorical concept existing in the reader's mind to what the author of the message, guided by a pragmatic task, is trying to generate in the reader. As a result of this interaction, the reader often changes his point of view, and his interpretation becomes similar to the interpretation of the journalist. In this regard the phenomenon is called reinterpretation of someone else's experience with the help of a metaphorical description (Gordon 1978).

Another important way of influencing the conceptual model existing in the mind of the reader is the use of folklore, images of famous characters, comparison of the described personality with another well-known character, as a result of which there is a comparison and imposition of metaphorical concepts. The information and experience specified in stories activate the reader's background knowledge. Further it is reinterpreted by the reader, thus forming an attitude toward the character. The conscious construction of metaphors and the use of folklore help the author of the message to solve specific pragmatic problems and, in particular, allow impacting a certain segment of the readers. This situation of indirect influence explains the phenomenon, noted by children's psychologists and received the following title: "Children love stories about how bees bite their grandfathers". Psychologically the interpretation of this fact runs as follows: memories of the failures of older relatives add confidence to children, once the others did not get everything right away, you should not be too upset about your mistakes. This phenomenon can explain the love of the mass media of economically less developed countries for stories about failures in the economy of rich countries.

\section{Conceptual Metaphors in Political Discourse}

How does the construction of metaphors in language and text occur? The principle of isomorphism becomes noteworthy in this case, when the participants and events of the known situation are transferred into the actors of the new situation. D. Gordon also emphasizes that in the experience of the 
recipient there are usually certain "triggers" that have the ability to cause positive and negative emotions. The task of the linguist acting as an imagemaker is to switch the metaphorical story and this triggers a more pleasant and useful experiment for the recipient (Gordon 1978).

One can imagine successful reports of a political plan, with a drastic increase in the proportion of metaphors, which, incidentally, corresponds to the studies of Dutch linguists who found that during periods of economic recession, there is an increase in the metaphorization of newspaper texts. The possible reason for this can be considered exactly the transition period and the absence of a clear and effective strategic plan for getting out of it. The description of the new realities should automatically cause metaphorization of language. The change of the political system also requires a rapid change of all the symbols in order to remove the positive associations that the past system evoked in relation to these symbols; in fact they act as "anchors" that induce positive emotions contradicting the new ideology. Thus, we can state that the conceptual metaphor performs an important function in shaping a public opinion. For example, the 1991 Gulf War specifically emphasized the importance of the conceptual metaphor in everyday life and in molding the reader's attitude toward politics as a whole. Exploring the metaphor used in the speeches of US President George W. Bush on the eve of the war, J. Trent concludes that metaphors played an important role in shaping public opinion toward Iraq's intervention in Kuwait (Trent 1993). The metaphorical concept of war is quite popular in the compilation of texts, the purpose of which is to combat drug abuse. Claiming that Iraq is a villain, and the US is a hero the US proved the intervention into Iraq.

In 1989 in the inaugural speech of George Bush Sr. the metaphoric usage of the concept of future time was represented through the expression of eyes fixed on the horizon, representing it as a great gift of freedom.

Some see leadership as high drama, and the sound of trumpets calling, and sometimes it is that. But I see history as a book with many pages, and each day we fill a page with acts of hopefulness and meaning. The new breeze blows, a page turns, the story 
unfolds. And so today a chapter begins, a small and stately story of unity, diversity, and generosity - shared, and written, together.

In this example history is compared with a book that tells us about the ideals of America. Each page of the book, turned over by a slight breeze, brings a new day with new actions.

In 1997 in Clinton's inaugural speech, time is compared with a bridge, the conceptual metaphor of a bridge that leads to the most wanted goal.

Let us shape the hope of this day into the noblest chapter in our history. Yes, let us build our bridge. $A$ bridge wide enough and strong enough for every American to cross over to a blessed land of new promise.

In George Bush Sr. inaugural speech in 1989 future is represented through the conceptual metaphor of door.

But this is a time when the future seems a door you can walk right through into a room called tomorrow.

Great nations of the world are moving toward democracy through the door to freedom. Men and women of the world move toward free markets through the door to prosperity. The people of the world agitate for free expression and free thought through the door to the moral and intellectual satisfactions that only liberty allows.

The metaphor of the open door will lead the nation to independence, prosperity and freedom.

\section{Conclusion}

The use of metaphors is quite common in American political discourse. Metaphor is a truly cognitive operation. It is a transfer or a projection of 
meaning from one conceptual field to another. Through conceptual metaphors American presidents capture and evoke different mental operations in the perception of reality. The analysis shows that conceptual metaphors used by American presidents are individually marked and appeal to the listener both intellectually and emotionally. The interpretation and decoding of metaphors is done in accordance with the context, the situation where it is used. We can conclude that the conceptual metaphor is a peculiar way of modeling the fragments of reality; it allows us to expand the boundaries of our knowledge. Creating a text about politics, the author of the message uses metaphorical concepts to influence the reader, just the same way as the author of a work of art does. The desired image of a politician is created with the help of both general language and deliberately created metaphoric concepts.

\section{References:}

1. Allbritton, D.W. (1994) When Metaphors Function as Schemas: Some Cognitive Effects of Conceptual Metaphors. // Metaphor and Symbolic Activity, 10:4.

2. Antropova, M.V. (1996) Lichnostnie Lichnostnye dominanty i sredstva ikh jazykovogo vyrazhenija (na materiale hudozhestvennyh tekstov). // Dis. .kand. filol. nauk. M.

3. Arutjunova, N.D. (1990) Metafora i diskurs. Vstupitel'naja stat'ja. // Teorija metafory. Moskva.

4. Black, M. (1962) More about Metaphors. // Ithaca, N.Y.: Cornell Univ. Press.

5. Chafe, W. (1967) Language as Symbolization Text. / W. Chafe. Language. Vol. 43.

6. Gordon, D. (1978) Therapeutic Metaphors. Helping Others through the Looking Glass. // Cupertino USA, Meta Publications, $1^{\text {st }}$ edition.

7. Glucksberg, S. (1990) Metaphor Understanding and Accessing Conceptual Schema: Reply to Gibbs (1992) Text. / S. Glucksberg, B. Keysar, M. McGlone. // Psychological Review, № 99.

8. Gusev, S.S. (1984) Nauka i metafora. L.: LGU. 
9. Gusev S.S. (1988) Uporjadochennost' nauchnoj teorii i jazykovye metafory. // Metafory v jazyke i tekste. M.: Nauka.

10. Jackendoff, R.; Aaron D. (1991) Review of Lakoff G., Turner M. "More Than Cool Reason: A Field Guide to the Poetic Metaphor". // Language.

11. Lakoff, G.; Johnson, M. (2003) Metaphors We Live by. Chicago: University of Chicago.

12. Lakoff, G.; Turner, M. (1989) More Than Cool Reason: a Field Guide to Poetic Metaphor. Chicago: The University of Chicago Press.

13. Reddy, M. (1980) The Conduit Metaphor. // Metaphor and Thought. Cambridge.

14. Trent, J.D. (1993) The Ideal Candidate: A Study of the Desired Attitude of the Public and the Media Across ... Campaigns. American Behavioral Scientist. N 2.

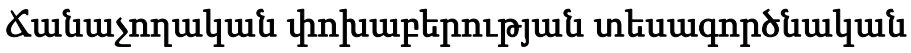 quauiuluntpjnıqu}

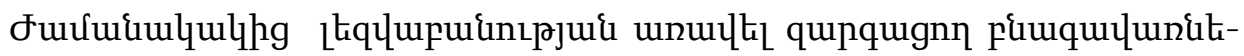

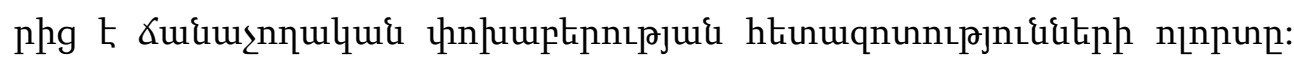

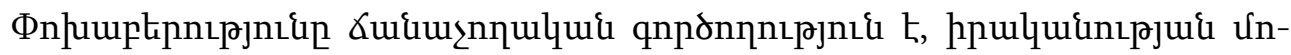

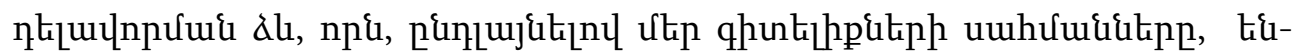

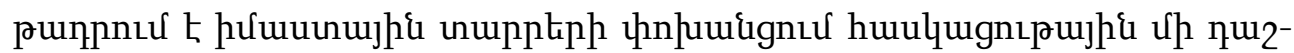

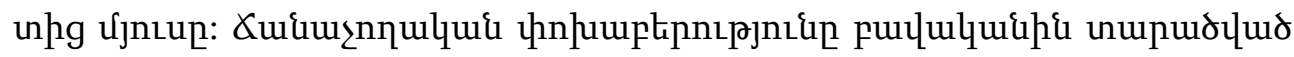

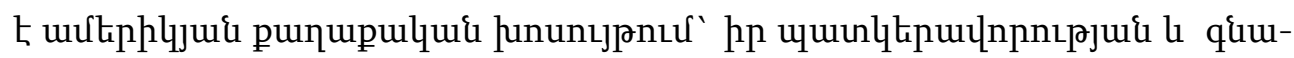

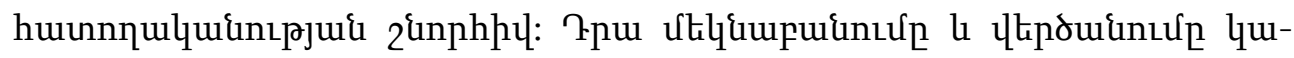

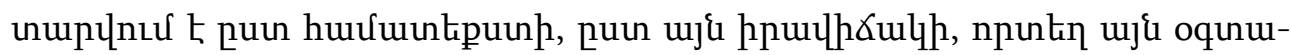

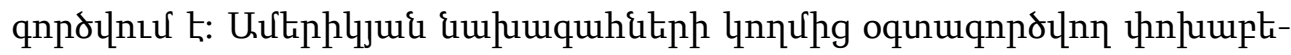

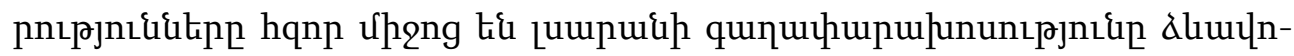
płįnı huugnud: 